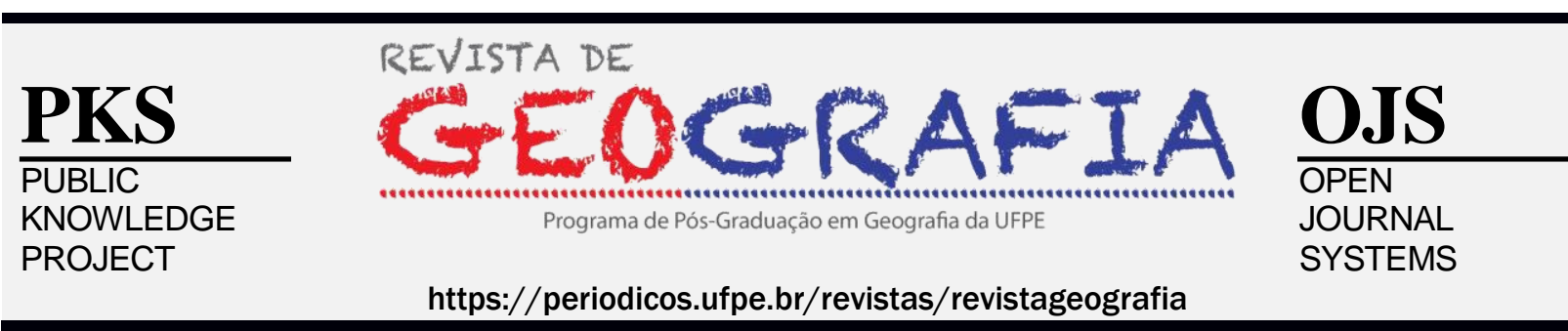

\title{
INDÍGENAS, TERRA E TERRITÓRIO EM ALAGOAS: UMA ANÁLISE GEOGRÁFICA DA ATUALIDADE DA RESISTÊNCIA
}

\author{
Lucas Gama Lima ${ }^{1}$, Amanda da Silva de Oliveira ${ }^{2}$, Anderson Ribeiro Miranda ${ }^{3}$
}

${ }^{1}$ Docente da Universidade Federal de Alagoas (UFAL). Email: lucas.lima@delmiro.ufal.br
${ }^{2}$ Graduanda da Universidade Federal de Alagoas (UFAL). E-mail: amanda.oliveira-55@hotmail.com
${ }^{3}$ Graduando da Universidade Federal de Alagoas (UFAL). E-mail: andersonr.m44@gmail.com

Artigo recebido em 28/05/18 e aceito em 14/11/18

\begin{abstract}
RESUMO
A formação territorial brasileira e alagoana alicerçou-se na usurpação das terras indígenas para as relações sociais de produção hegemônicas. Tal fato resultou na eliminação física de indígenas e dispersão/desaparecimento de etnias. Entretanto, ao longo do século XX, em especial, após a ditadura civilmilitar, diversos grupos indígenas assumiram, publicamente, sua condição étnica, passando a buscar a retomada de suas terras para a construção do seu território. Na presente investigação, busca-se analisar a formação territorial alagoana e seus desdobramentos para os povos nativos. É igualmente analisada a emergência de etnias indígenas no estado de Alagoas e o processo desencadeado de lutas, como expressão viva das contradições territoriais. Como suporte teórico à análise, é realizada uma discussão conceitual de terra e território, a partir de autores da Geografia e de outros ramos das Ciências Humanas, buscando decodificar suas expressões semânticas, no contexto da questão indígena. Por fim, são tecidas considerações sobre o quadro atual da luta por terra e território indígenas, em Alagoas, observando dados e informações sobre regularização fundiária, violação de terras, assassinatos e ameaças de morte. Trata-se de uma contribuição analítica de base teórico-empírica, que visa fornecer elementos para o entendimento da situação contemporânea vivenciada pelas etnias indígenas em Alagoas.
\end{abstract}

Palavras-chave: formação territorial; terra; território; capital.

\section{INDIGENOUS PEOPLE, LAND AND TERRITORY IN ALAGOAS: A GEOGRAPHIC ANALYSES OF TODAY'S RESISTANCE}

\begin{abstract}
The territorial formation of Brazil and Alagoas was built on the usurpation of indigenous lands for the social relations of hegemonic productions. This has resulted in the physical disposal of indigenous people and dispersion/demise of ethnicities. Nonetheless, throughout the XX century, in particular, after the military dictatorship, a number of indigenous groups undertook, publicly, their ethnic condition, turning to search the resumption of their lands for the construction of their territory. In the present investigation is sought to analyse the territorial formation of Alagoas and its developments for indigenous people. It is also analysed the emergence of indigenous ethnicities in the state of Alagoas and the triggered process of struggles, as a vivid expression of territorial inconsistencies. As theoretical support to the analyses, it is performed a conceptual discussion of land and territory, based on authors of Geography and other areas of Human Science, searching to decode their semantic expressions, in the context of the indigenous issue. Finally, considerations are made about the current scenario of struggles for indigenous land and territory, in Alagoas, observing data and information about the landholding regularization, violation of lands, assassinations and death threats. It is an analytical contribution with theoretical-empirical reference, which aims provide elements for the understanding of the contemporary situation experienced by indigenous ethnicities in Alagoas.
\end{abstract}


Keywords: territorial formation; land; territory; capital.

\section{INTRODUÇÃO}

A invasão colonial portuguesa no Brasil entabulou uma relação social ancorada no trabalho escravo e na produção monocultora para exportação. Nessa trama, os povos originários foram, violentamente, expropriados no bojo de uma acumulação primitiva do capital (Porto-Gonçalves, 2002; Oliveira, 2016), que atravessou séculos. A formação territorial brasileira decorreu do engendramento de relações sociais de produção que, conforme explicou Moraes (2000), centraram-se na eliminação e subordinação dos indígenas ao empreendimento mercantil.

A independência política do país e, décadas mais tarde, a proclamação da República, não passaram de epifenômenos de um arranjo social, que consolidou o avanço do capital sobre as terras - vide a Lei de Terras de 1850 - e, por sua vez, o beneplácito para a dizimação ou incorporação dos indígenas à sociedade nacional, num deliberado processo de aculturamento.

Não obstante, os povos originários do país resistiram. O processo multissecular e institucional de desterritorialização gerou um processo de reterritorialização desses povos, que ganhou impulso com o fim da ditadura civil-militar e a promulgação da Constituição Federal de 1988. Indígenas que se encontravam dispersos, ocultando seus vínculos étnicos como mecanismo de proteção, ousaram assumir, publicamente, sua condição (Vieira, 2013). As lutas pela retomada de terras, anteriormente, usurpadas e a conquista de novas terras tornaram-se corriqueiras entre as etnias indígenas.

Em Alagoas, um estado da federação cuja formação territorial esteve (e ainda está) vinculada ao latifúndio e ao poder oligárquico de base agrária, a luta territorial indígena costuma ser tratada com o repugnante uso da violência, mediante ameaças e assassinatos.

Nesta investigação é apresentada uma análise acerca da formação territorial alagoana, inscrevendo-a no contexto nacional do avanço do capital sobre as terras dos indígenas. Busca-se igualmente apresentar a emergência das etnias e o desencadeamento da retomada e da conquista de novas terras, no bojo de sua luta pela construção do território. É realizada uma revisão bibliográfica, objetivando apresentar, em breves linhas, a discussão conceitual sobre o território e a terra indígenas, bem como, a contraposição que antagoniza o território indígena frente ao capital. Em seguida, serão apresentados e discutidos os dados e as informações acerca da luta por terra e território em Alagoas, dando ênfase à análise da 
situação atual da regularização fundiária e dos ataques sofridos pelos indígenas, em especial, a violação de suas terras, assassinatos e ameaças de morte.

Para a consecução desses propósitos, passaremos em revista nos escritos de autores da Geografia, a exemplo de Moraes (2000), Porto-Gonçalves (2002) e Oliveira (2016) e de autores de outras áreas das Ciências Humanas, a saber, Gallois (2004), Oliveira (2006), Luciano (2006), Maria da Silva (2008), Amaro da Silva (2009), Martins (2010), Vieira et al (2013), dentre outros.

Os dados e as informações presentes no texto são oriundos de fontes primárias e secundárias. Como fonte primária, foram feitas visitas aos povos Geripankó e Kalankó. Como fontes secundárias, foram consultados os Relatórios de Violência Contra os Povos Indígenas no Brasil, no período de 2003 a 2017, elaborados e disponibilizados pelo Conselho Indigenista Missionário (CIMI). São também usados dados e informações da Fundação Nacional do Índio (FUNAI), da Secretaria Especial de Saúde Indígena (SESAI) e de matérias jornalísticas extraídas da internet. Faz-se necessário registrar que foram empregados dados obtidos junto à Coordenação Regional Nordeste I da FUNAI, por meio do Sistema Eletrônico do Serviço de Informação ao Cidadão (e-SIC), do Portal da Transparência, conforme Lei $12.527 / 11$.

A sistematização dos dados e das informações e a confecção dos mapas foram realizados no âmbito do Observatório de Estudos e Pesquisas sobre a Luta por Terra e Território (OBELUTTE), vinculado ao Grupo de Estudos e Pesquisa em Análise Regional (GEPAR/CNPq), situado no Campus do Sertão da UFAL.

Espera-se com esse artigo oferecer mais uma contribuição analítica aos estudos da ciência geográfica, por meio da investigação da realidade contemporânea das etnias indígenas de Alagoas, em sua busca por terra e território.

\section{A QUESTÃo INDÍGENA NA FORMAÇÃO TERRITORIAL ALAGOANA: UMA OPRESSÃO QUE ATRAVESSA SÉCULOS}

A formação territorial alagoana foi construída a partir da invasão dos portugueses, que deflagram o empreendimento monocultor canavieiro no litoral do estado, esbulhando as terras indígenas e engendrando a dispersão e o desaparecimento de algumas etnias, a exemplo dos Caetés, implacavelmente, perseguidos no século XVI.

A dispersão dos povos indígenas, levou-os a perquirir sua (re)territorialização no interior do continente, num processo, permanentemente, marcado pela instabilidade, em face 
da progressiva expansão da atividade econômica colonial, que usurpou as terras a oeste (Agreste e o Sertão) da mancha litorânea para a pecuária e para o algodão.

O projeto da empresa colonial foi implantado em três etapas regionais litoral, agreste, sertão -, articulando a invasão territorial e a espoliação material e espiritual dos bens naturais, culturais e religiosos (VIEIRA et al, 2013, p. 183; 184).

No século XVIII, foram criados os aldeamentos, destinados aos indígenas considerados "não hostis" pelo Estado e, geralmente, administrados por religiosos. Tratou-se de uma ação coercitiva, que inseriu diversas etnias dentro de uma área delimitada, com o fito de controlá-los, por meio do aculturamento e do uso de sua força-de-trabalho nas fazendas.

A política de aldeamento foi essencial para o projeto de colonização. Afinal, os índios aliados eram indispensáveis ao projeto, pois além de compor as tropas militares, eles deviam ocupar os espaços conquistados e contribuir, como mão de obra, para a construção das sociedades coloniais. Desempenharam importantes funções e foram, grosso modo, estabelecidos e administrados por missionários, principalmente por jesuítas (ALMEIDA, 2010, p. 71).

O fim da colonização portuguesa, em 1822, e o advento da transição do Império para a República, em 1899, não resultaram no reconhecimento, por parte do Estado, dos ataques desferidos contra a autodeterminação dos povos indígenas, em mais de três séculos. Um obstáculo crucial se opôs à questão indígena: a transformação da terra em mercadoria. Conforme nos explica Martins (2010), desde a Lei de Terras de 1850 a terra tornou-se cativa, objeto passível de compra e venda, além de base material do poder político das famílias abastadas, também chamadas de oligarquias.

Desse modo, como a estrutura fundiária brasileira seguiu marcada pela presença da grande propriedade - o latifúndio - juridicamente respaldada e contando com a proteção estatal, a questão indígena foi negada. Por serem marginalizados e concebidos como caboclos, os aldeamentos foram encerrados nas décadas finais do século XIX, numa evidente tentativa de dissolver os pleitos dos indígenas no bojo do interesse da sociedade nacional.

A política de extinção das aldeias é na verdade um desdobramento do avanço da sociedade nacional sobre os territórios indígenas. Se numa primeira etapa serve para determinar o que não é território indígena liberando a terra para a conquista, num segundo momento nem mesmo as terras da aldeia serão preservadas. Em relação à identificação às populações indígenas isto vai significar que o índio aldeado que em princípio era o 
caboclo, passe a ter sua própria existência negada porque agora já era miscigenado (SILVA, 2008, p. 121; 122).

Campos (2013) explica que a extinção dos aldeamentos no Brasil ocorreu de várias maneiras. Em Alagoas, os aldeamentos foram extintos através de um decreto, datado de 1872, e expedido pelo então presidente da província, Luiz Rômulo Peres de Moreno. Tal medida representava uma tentativa de silenciar os indígenas (Silva Júnior, 2013), facilitando a narrativa oficial de seu suposto desaparecimento e/ou integração à denominada sociedade nacional. Adicionalmente, também proporcionava a futura apropriação dessas terras pelas oligarquias agrárias e o aumento do contingente de indígenas disponíveis para a venda de sua força de trabalho, em meio a um contexto de expansão das relações capitalistas no campo.

A expansão capitalista ocorrida na passagem do século XIX para o XX, gerou inúmeras consequências para as populações indígenas que habitavam as regiões brasileiras, já que a partir daí, surgiram vários conflitos fundiários devido aos processos de colonização do território (SANTANA JÚNIOR, 2010, p. 210).

Desterritorializados e taxados como remanescentes em via de desaparecimento, parte dos indígenas de Alagoas se dispersou, negando, frequentemente, sua própria identidade étnica, como mecanismo de proteção ao preconceito e a outras manifestações de opressão. Outra parte sujeitou-se à tutela do Serviço de Proteção ao Índio (SPI), por meio da qual, de acordo com Oliveira (2006), a condição indígena era concebida como transitória, e o Estado executava uma política indigenista, destinada a converter o índio em um trabalhador nacional, mediante métodos e técnicas educacionais homogeneizantes. O tutelamento entabulado pelo SPI era, notadamente, contraditório, pois

enquanto se propunha a respeitar as terras e a cultura indígena, agia transferindo índios e liberando territórios indígenas para colonização, ao mesmo tempo em que reprimia práticas tradicionais e impunha uma pedagogia que alterava o sistema produtivo indígena (OLIVEIRA, 2006, p. 115).

Contradição, inclusive, apontada por Darcy Ribeiro (2017), quando expôs que o SPI cometeu erros durante a tentativa de integração dos indígenas à sociedade nacional, haja vista que não conseguiu impedir a usurpação de suas terras e a proliferação da fome e de doenças.

Em síntese, durante a maior parte do século XX, os indígenas serão concebidos como reminiscências de um passado cada vez mais distante, não sendo tratados como povos, mas como indivíduos em franca assimilação à sociedade nacional, sob a tutela do Estado. O fim $\begin{array}{llr}\text { dos } 21 \text { anos de ditadura civil-militar no Brasil, em 1985, permitiu o (res)surgimento de } & \text { ISSN 0104-5490 }\end{array}$ 
diversas pautas de cunho social, dentre elas, a questão indígena. Várias etnias, que por força de séculos de repressão ocultaram suas identidades (Luciano, 2006), passaram a assumir, publicamente, seu vínculo étnico e a pleitear a retomada de suas terras. Segundo Campos (2003, p. 74), o ato de retomada dirigido pelos indígenas significa "buscar de volta aquilo que os pertence desde sempre".

A inscrição na Constituição de 1988 de um capítulo dedicado à questão indígena resultou de "unidades de mobilização" (ALMEIDA, 1989, p. 7), articulando escalas de reivindicação (Cruz, 2011), que forçou a República Brasileira a reconhecer diversos povos indígenas, seu direito às terras e à construção de seus territórios.

A emergência - qualificada de etnogênese ${ }^{1}$ nos estudos da Antropologia - e a retomada das terras, no último quartel do século XX, tiveram destaque em Alagoas. Somaram-se aos Xukuru-Kariri e aos Kariri-Xocó - já envolvidos nesse processo há décadas - mais dez etnias, que protagonizaram ações públicas em todas as regiões do estado para conferir visibilidade à reivindicação pelo reconhecimento étnico e demarcação das terras (Vieira, 2013).

Desde então, existem no estado de Alagoas 12 etnias indígenas, a saber: Aconã, Geripankó, Kalankó, Karapotó, Kariri-Xocó, Karuazu, Katokinn, Koiupanká, Pankararu, Tingui-Botó, Xukuru-Kariri e Wassu-Cocal. Salienta-se que a etnia Pankararu, situada no município de Delmiro Gouveia, ainda não consta nos registros da FUNAI, mas dispõe do reconhecimento de outras etnias.

Conforme o Censo Demográfico (2010), foram identificadas 16.291 pessoas que se autodeclararam indígenas em Alagoas, sendo 6.268 residentes nas aldeias e 10.023 não residentes. Entretanto, esses números não coincidem com a estimativa de população indígena, divulgada pela Secretaria Especial de Saúde Indígena (SESAI), vinculada ao Ministério da Saúde. Segundo a SESAI apud FUNAI (2018), existem mais de 20 mil indígenas espalhados por todo o estado de Alagoas, sendo 11.887 indígenas vivendo em aldeias. De acordo com a Funai (2018), a referida discrepância das estatísticas oficiais decorre da ausência de critérios comuns, entre os órgãos, para a identificação de alguém como indígena.

Na figura 1, estão espacializadas as etnias indígenas do estado de Alagoas. É possível observar que as mesmas estão distribuídas espacialmente nas três Mesorregiões: Leste, Agreste e Sertão. Na figura 2, consta a estimativa populacional de indígenas por etnia. As etnias Wassu-Cocal, Kariri-Xocó e Xukuru-Kariri se destacam pela elevada quantidade de

\footnotetext{
${ }^{1}$ A etnogênese é qualificada por Bartolomé (2006) como o reaparecimento no cenário social de grupos étnicos outrora dados como extintos. 
indígenas vivendo nas aldeias. No Sertão de Alagoas, extremo oeste do estado, os Geripankó se notabilizam com o maior contingente populacional.

\section{Figura 1: Localização das etnias indígenas de Alagoas}

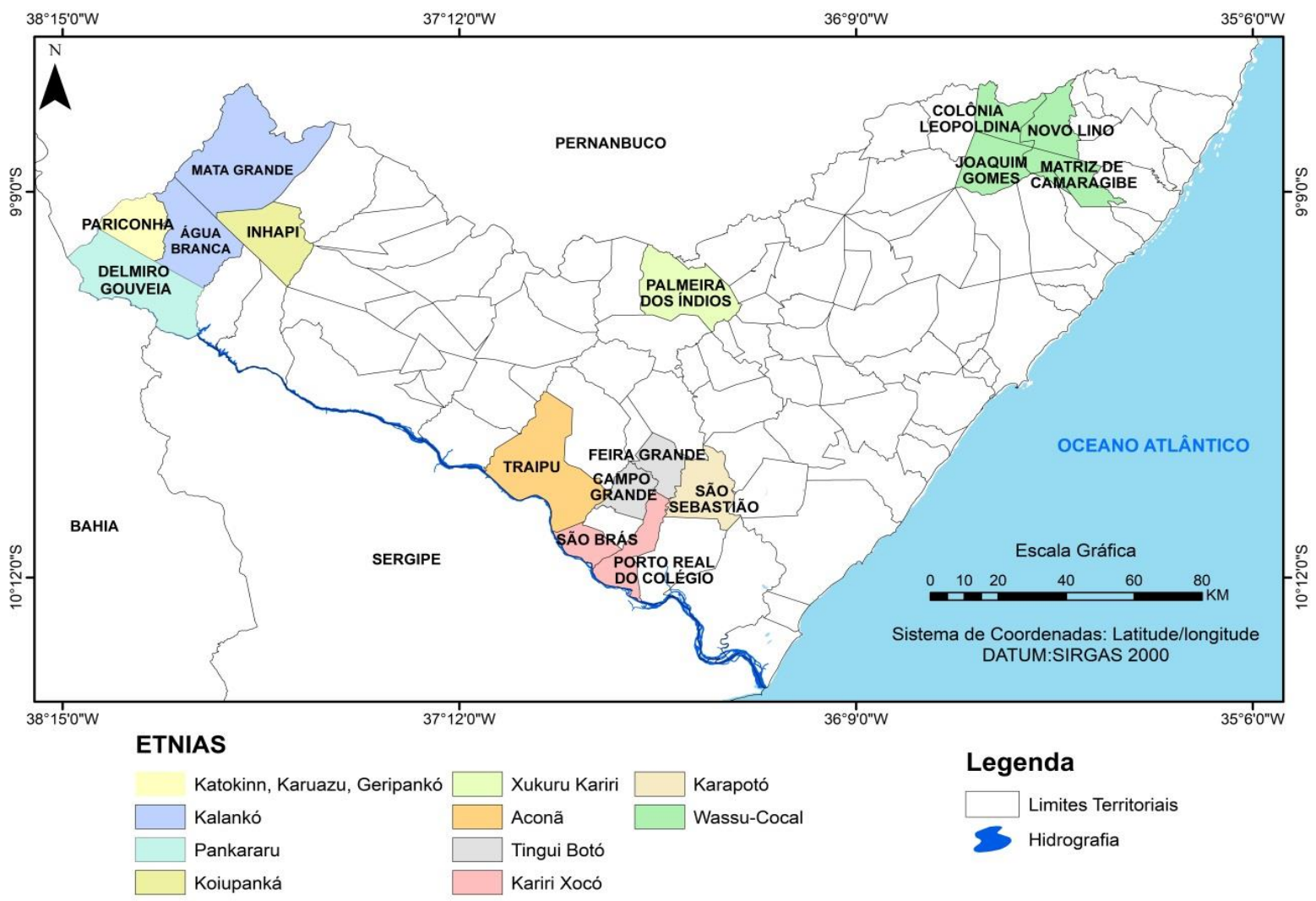

Fonte: SEPLAG, 2017; FUNAI, 2018; Trabalho de campo. Organização: própria 


\section{Figura 2: Quantidade de indígenas aldeados por etnia (2018)}

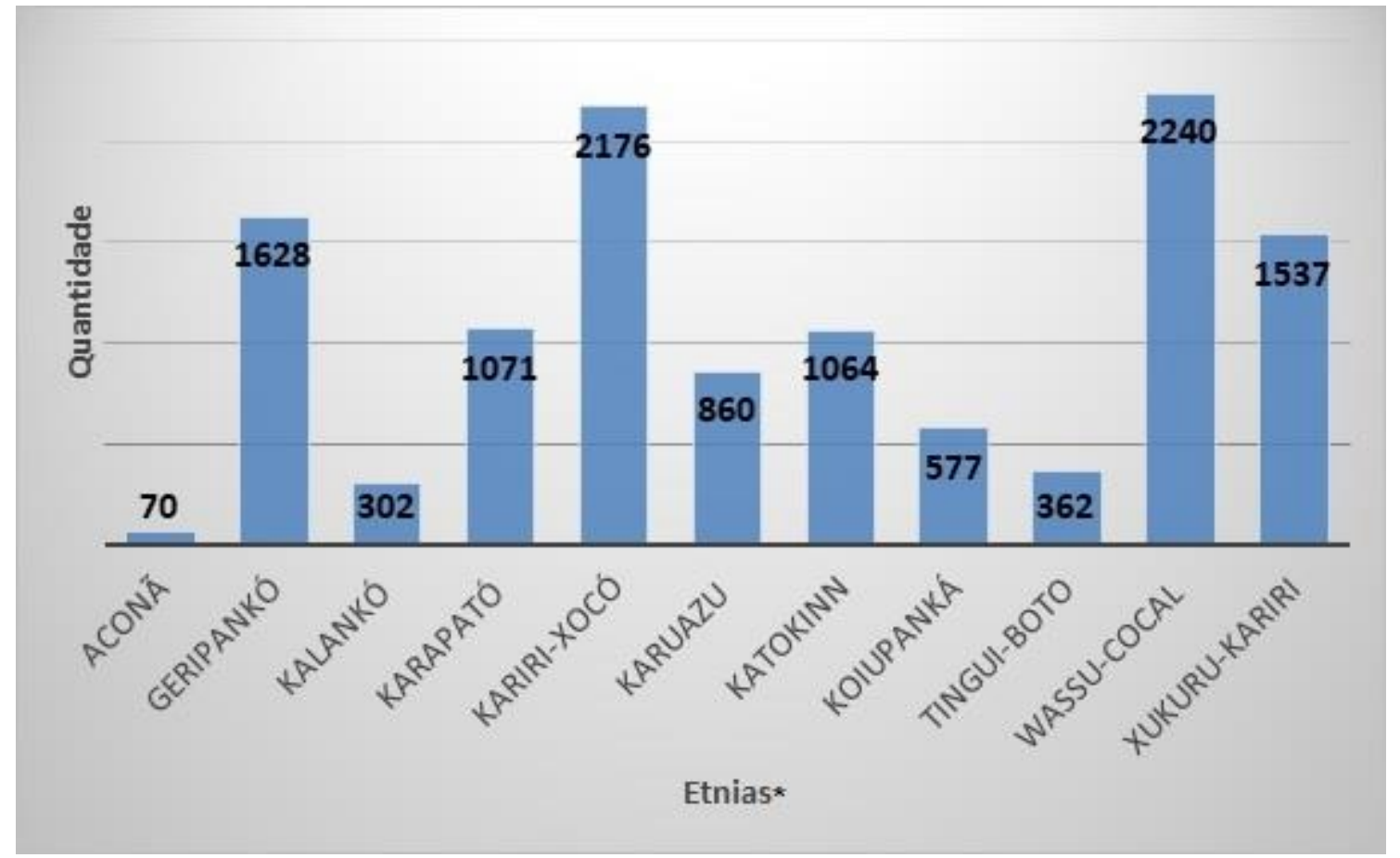

Fonte: FUNAI, 2018. Organização: própria.

*A FUNAI não disponibiliza informação sobre a etnia Pankararu.

\section{TERRA E TERRITÓRIO INDÍGENAS: BREVES CONSIDERAÇÕES CONCEITUAIS}

Refletir sobre os indígenas de Alagoas implica estabelecer uma análise sobre seus objetos centrais de reivindicação, quais sejam: terra e território.

Para esses sujeitos, o território é o elemento fundamental para a produção e a reprodução de suas vidas. É através do território que se assegura a cristalização das condições materiais e imateriais que (res)significam, permanentemente, sua condição étnica e social. Não somente o cultivo na terra, a criação de animais, a coleta de água, a extração de frutos e de outros elementos da natureza, como também, os torés, os encantados, os praiás, as sementes, os rituais e as festas (Ouricuri, a Flechada do Umbu, Menino do Rancho, dentre tantas outras ${ }^{2}$ ) povoam a ação e o cosmus desses povos.

Território é condição para a vida dos povos indígenas, não somente no sentido de um bem material ou fator de produção, mas como o ambiente em que se desenvolvem todas as formas de vida. Território, portanto, é o conjunto de seres, espíritos, bens, valores, conhecimentos, tradições que garantem a possibilidade e o sentido da vida individual e coletiva (LUCIANO, 2006, p. 101).

${ }^{2}$ Rituais e festas encontradas nas etnias indígenas situadas em Alagoas. 
Nesse sentido, o território indígena se estabelece mediado por uma territorialidade própria, que congrega uma relação sociedade/natureza, na qual a água, o ar, a terra, a fauna e a flora e os acidentes geográficos integram sua prática social. Muito mais que uma parcela do espaço geográfico apropriada, a singularidade do território indígena está assentada na combinação de uma produção social onde a terra oferece os elementos necessários à vida material e imaterial.

Vale registrar que o território indígena está situado em contraposição ao território do capital. Por constituir-se por meio de uma relação social na qual os diversos elementos da natureza (água, ar, solo, fauna e flora e acidentes geográficos) não são meros recursos naturais, senão a fonte onde radica a possibilidade de perpetuação da etnia e a lógica explicativa da existência, o território indígena contraria o dínamo que alimenta a valorização do capital.

O ritmo compassado do tic-tac do relógio no seu descolar temporal nunca foi a marcação do tempo para as nações indígenas. Lá, o fluir da história está contado pelo passar das "luas" e pela fala mansa dos mais velhos registrando os fatos reais e imaginários (OLIVEIRA, 2016, p. 178).

O capital está orientado ao processo ininterrupto de acumulação, condição que se potencializa no atual contexto de economia mundializada, onde os meios de produção funcionam como meios de destruição (Mészáros, 2002). Nesse sentido, os operadores do capital - corporações empresariais e o Estado - tratam o território indígena como um fundo territorial, passível de apropriação: nele, existem somente recursos naturais não explorados.

A tirania do tempo célere, do tempo do capital, não admite uma lógica territorial que a obstaculize. Daí a relação sociedade/natureza, própria das comunidades indígenas, bem como, o movimento de reivindicação das terras, protagonizado pelos povos indígenas no país, funcionarem como antítese dialética aos imperativos do capital (Mizusaki, 2017). Uma verdadeira contradição territorial, que somente pode ser decodificada, se tomarmos como pressuposto a vigência de territórios distintos (Lira, 2015): o território indígena, sob a hegemonia do valor de uso; e o território do capital, hegemonizado pela valorização do valor.

Os povos indígenas no país, historicamente expropriados na formação territorial brasileira, num processo multissecular de acumulação primitiva do capital (Porto-Gonçalves, 2002), seguem buscando a permanência ou a construção de seus territórios, anteriormente usurpados (Bethonico, 2018), uma contradição territorial que permanece atual no tempo histórico vigente. 
No âmbito da discussão sobre o significado do território para os povos indígenas, uma questão se apresenta de modo pertinente: a distinção entre a terra e o território. Embora pareçam diferentes denominações para o mesmo fenômeno, terra e território indígenas dão origem a conceitos, qualitativamente, distintos, porém, associados. De acordo com Oliveira (2016), a terra é o espaço da produção, do labor agrícola, do uso do solo, que comporta, mais precisamente, uma definição jurídica. Ainda segundo Oliveira (2016), o território indígena é mais abrangente que a terra.

Luciano (2006), igualmente, identifica uma diferença entre a terra e o território indígenas, sendo a terra concebida como o espaço geográfico, onde radicam as bases para a possível existência do território. Este, por sua vez, tratado de modo mais abrangente e completo.

Acerca desse debate, Gallois (2004) preconiza uma perspectiva próxima às acepções ora apresentadas. Corrobora que terra e território não se equivalem conceitualmente e associa a noção de terra indígena à delimitação oficial do Estado, portanto, a um processo de caráter político-jurídico, que não contempla a complexidade da condição étnica e social indígena.

Em que pese a terra ser objeto de delimitação por parte do Estado e está sob determinação jurídico-política, partimos do pressuposto de que terra e território possuem conceitos distintos, porém imbricados na dinâmica da luta empreendida pelos povos indígenas. A terra é o lócus da produção, espaço geográfico elementar para o estabelecimento da produção material. Assim, a terra é imprescindível para a existência do território e complementa-o (Montenegro, 2010).

Por outro lado, o território indígena se aproxima do que seria o seu habitat (Oliveira, 2016), constituindo uma sui generis combinação de atividade produtiva na terra, junto à cosmologia e manifestação cultural (territorialidades), que fundamentam a origem e orientam a ação. O território permite contemplar com maior clareza a complexa relação étnica e social dos indígenas, ao tempo que demarca, perante o Estado e a sociedade nacional, a maneira particular de organização e interação com a natureza desses povos. Em síntese, ambos, terra e território unificam e impulsionam o movimento de resistência indígena contemporâneo no Brasil (Luciano, 2006), sendo fundamentais para o seu entendimento. 


\section{O QUADRO ATUAL DA LUTA POR TERRA E TERRITÓRIO INDÍGENAS EM}

\section{ALAGOAS}

A etnogênese e o fortalecimento do movimento indígena pós-ditadura, em Alagoas, permitiram o processo de luta/retomada das terras para a construção do território indígena, no qual seja factível o estabelecimento de uma prática social, de expressão material e imaterial, construída autônoma e coletivamente. Buscam a regularização de suas terras por parte do Estado, como condição basilar à conformação do território indígena. Nesse sentido, terra e território são duas dimensões da luta que estão devidamente imbricadas no cerne das reivindicações desses sujeitos.

Atualmente, das 12 etnias de Alagoas, apenas duas possuem sua situação fundiária, oficialmente, regularizada. As demais etnias continuam pressionando para o andamento mais célere do rito processual de formalização integral de suas terras perante o Estado.

Quadro 1: Situação fundiária das terras pleiteadas pelas etnias

\begin{tabular}{|c|c|}
\hline Etnias & Situação Fundiária \\
\hline Aconã & Não regularizada \\
\hline Geripankó & Não Regularizada \\
\hline Kalankó & Não Regularizada \\
\hline Karapotó & Regularizada \\
\hline Kariri-Xocó & Não Regularizada \\
\hline Karuazu & Não Regularizada \\
\hline Katokinn & Não Regularizada \\
\hline Koiupanká & Não Regularizada \\
\hline Pankararu* & Regularizada \\
\hline Tingui-Botó & Não Regularizada \\
\hline Wassu-Cocal & Não Regularizada \\
\hline Xukuru-Kariri & \\
\hline
\end{tabular}

Fonte: CIMI, 2016; SEPLAG, 2017; FUNAI, 2018. Organização: própria.

* Não há informação sobre a situação fundiária dos Pankararu.

É forçoso argumentar que a regularização das terras, embora configure uma pauta fundamental, não assegura o gozo do território por parte das comunidades indígenas, pois nem sempre o tamanho das terras regularizadas é suficiente para o atendimento das diversas

$\begin{array}{lll}\text { Lima et al., } 2019 & \text { ISSN 0104-5490 }\end{array}$


demandas da comunidade indígena. Como exemplo, registra-se o caso dos Karapotó, cujas terras da comunidade foram regularizadas, mas a área da reserva se mostrou insuficiente para a continuidade da construção do território indígena.

Ademais, a lógica expansiva do capital investe contra as terras regularizadas e não regularizadas dos povos tradicionais, buscando sujeita-las aos imperativos frenéticos de acumulação. Obviamente, as terras indígenas sem regularização padecem de maior fragilidade, estando mais vulneráveis a toda sorte de ataques. Podem ser apresentados, pelo menos, dois exemplos desses ataques à construção dos territórios indígenas em Alagoas: a) violação das terras por parte de fazendeiros, empresas de mineração e construção civil, além de posseiros e; b) deliberados assassinatos e ameaças várias contra os indígenas.

\section{VIOLAÇÃO DAS TERRAS INDÍGENAS.}

A luta pela construção do território indígena é marcada por constantes conflitos, numa estrutura agrária altamente concentrada e dominada por oligarquias, que comandam a vida política e econômica do estado de Alagoas. O reconhecimento da etnia e a regularização das terras não são suficientes para o exercício de domínio pleno, por parte dos indígenas, em seu território, haja vista que a mais que secular omissão do Estado com a questão indígena e a hegemonia das relações sociais, comandadas pelo capital, entabularam o desrespeito aos povos tradicionais.

Viera (2015) apud Seplag (2017) aponta que os Xukuru-Kariri, situados no município de Palmeira dos Índios, enfrentam essa vulnerabilidade, pois suas terras são, constantemente, violadas por fazendeiros, por posseiros e, inclusive, pelo poder municipal. Em um dos vários conflitos registrados, os indígenas denunciaram a contaminação por agrotóxico de nascente de um dos rios que serve para abastecimento da comunidade. Ao visitar o local da denúncia a Fiscalização Preventiva Integrada da Bacia Hidrográfica do São Francisco (FPI), liderada pelo Ministério Público de Alagoas (MP/AL), constatou que havia também a supressão da vegetação nativa. As irregularidades eram cometidas por um fazendeiro (G1, 2015).

Situação semelhante pode ser encontrada nas aldeias das etnias indígenas dos Geripankó, Kalankó, Karuazu, Katokinn e Koiupanká. São etnias que vivem no Sertão alagoano, provenientes de um deslocamento espacial do Sertão de Pernambuco, ainda no século XIX, em razão de desterritorialização promovida por criadores de gado, num ataque que permaneceu na memória dos indígenas como o "tempo das linhas" (Silva, 2009). Os membros dessas etnias são obrigados a dividir as terras de seu território com posseiros da 
região, causando conflitos regulares acerca da gestão dos elementos da natureza presentes. Em entrevista que nos foi concedida, duas lideranças das etnias Geripankó e Kalankó afirmaram, respectivamente:

A situação de nosso território continua parada em Brasília e várias pessoas não-índias estão aqui. (Aldeia Ouricuri, entrevista realizada em 03/10/2017).

Nossas terras estão cheias de gente que não pertence à tribo, é complicado viver assim. O cuidado com nossa água está prejudicado. (Aldeia Januária, entrevista realizada em 21/10/2017).

Nas aldeias dos Kalankó, os indígenas costumam arrendar superfícies dentro das terras tradicionalmente ocupadas para que possam plantar, tornando oneroso um ato elementar da vida, a saber, a alimentação. Salienta-se que, não obstante outras determinações, a "ausência de condições mínimas para a produção de alimentos em seu próprio território exerce uma influência deveras significativa para a saída do indígena da Aldeia e sua consequente proletarização" (LIMA; SILVA; FEITOZA, 2018, p. 1112). Diante da exiguidade das terras, alguns indígenas da etnia Kalankó, como indígenas das demais etnias do Sertão de Alagoas, especialmente, jovens e do sexo masculino, costumam migrar para o corte da cana-de-açúcar na Zona da Mata de Alagoas ou para outros estados do país. Lá, são empregados em atividades agrícolas ou na construção civil. Entre os Geripankó é igualmente comum o arrendamento de superfícies agrícolas ou a venda da força-de-trabalho a posseiros, dentro das terras tradicionalmente ocupadas. Também se registra a mobilidade espacial do trabalho para o corte da cana na Zona da Mata de Alagoas, conforme explica Albuquerque e Caniello (2015).

As terras indígenas da etnia Wassu-Cocal, situadas na parte norte da Mesorregião Leste de Alagoas, tornaram-se alvo da invasão de um empreendimento ilegal de exploração mineral. Em ação da Polícia Federal, realizada em 2012, três pessoas foram presas, acusadas de extração não autorizada de granito, uso de trabalho escravo e desmatamento da vegetação nativa (Alagoas 24horas, 2012). Os Kariri-Xocó, situados no extremo sul do estado, não ficaram ilesos às violações. Em 2014, diversos órgãos públicos identificaram a construção de casas de veraneio e pousadas, por parte de empresários, dentro das terras habitadas pelos indígenas. As edificações estavam localizadas às margens do rio São Francisco e em área de preservação permanente (CIMI, 2014). Antes, em 2010, um pecuarista sergipano havia sido condenado, após denúncia feita pelo Ministério Público Federal de Alagoas (MPF/AL) de desmatamento para a criação de gado, no interior das terras dos Kariri-Xocó. O procedimento 
usado na ocasião, para a retirada ilegal da vegetação, era um dos mais danosos à natureza: o famigerado "correntão" - correntes puxadas por tratores que extraem toda a árvore, impedindo sua regeneração (Ecodebate, 2010).

Como se pode notar, os povos indígenas de Alagoas são alvos frequentes de ações que colocam em xeque suas terras e a construção de seus territórios. Além dos conflitos com posseiros, há uma deliberada investida do capital, por meio de empresas de mineração, de construção civil e do ramo imobiliário, além de fazendeiros criadores de gado, que intentam subtrair parcelas das terras ou usurpar os elementos da natureza presentes nas mesmas.

\section{ASSASSINATOS E AMEAÇAS AOS INDÍGENAS}

A luta pelo direito às terras e à construção dos territórios indígenas costuma ser exercida em uma situação que impõe riscos à integridade física de membros das etnias. Entre os Kalankó existem indígenas que sofrem ameaças de morte, decorrentes da obstinada denúncia feita por essa etnia acerca da presença de não-índios em suas terras. Nestas, existem de pequenos posseiros a indivíduos de grande influência na região, que adotam a intimidação como ferramenta ordinária de repressão aos indígenas Kalankó.

Os Karapotó, situados no Baixo São Francisco, extremo sul de Alagoas, vivenciam situação similar. Não obstante estivessem em terras de reserva, o tamanho disponibilizado não atendia às demandas da condição indígena e a dinâmica de crescimento da etnia. Em razão disso, protagonizaram lutas de retomada de suas terras, invadidas por fazendeiros da região. Como consequência, em 2011, sofreram com intimidações feitas por pistoleiros, contratados por fazendeiros $(\mathrm{G} 1,2011)$.

Não raramente, as ameaças de violência emanam de agentes do Estado. Em 2011, policiais federais adentraram as terras retomadas e reivindicadas pelos Xukuru-Kariri. Na ocasião, com a companhia de um gerente da fazenda, que incide sobre as terras retomadas, tomaram fotos sem autorização dos indígenas, ameaçando-os verbalmente, numa flagrante tentativa de intimidação (CIMI, 2011). Sobre os mesmos Xukuru-kariri houve um caso mais recente. Em 2016, após retomada da fazenda Jarro, o fazendeiro se dirigiu aos indígenas e fez uso de notável violência verbal, buscando conter a luta dos indígenas para reaver suas terras.

As ameaças podem se desdobrar na consumação de assassinatos de indígenas. A subtração da vida de membros dos povos nativos no país data, como já tratado, da invasão colonial portuguesa. Acompanhou a formação territorial brasileira e permanece até os dias atuais, mesmo após a assunção da Constituição Federal de 1988. Somente nos últimos 15 
anos, foram registrados os assassinatos de mais de 1000 índios. As mortes, geralmente, estão associadas à luta de resistência à invasão de suas terras pelo capital - especialmente, nos estados da região Centro-Oeste e na porção espacial do MATOPIBA ${ }^{3}$, áreas de expansão do agronegócio - e à retomada das terras para a construção do território indígena. Na figura 3, consta a distribuição dos assassinatos de indígenas entre 2003 e 2017. Chamam atenção os números registrados no período de 2014 a 2017, pois ultrapassaram a marca de 100 assassinatos por ano.

\section{Figura 3: Quantidade de indígenas assassinados no Brasil (2003-2017)}

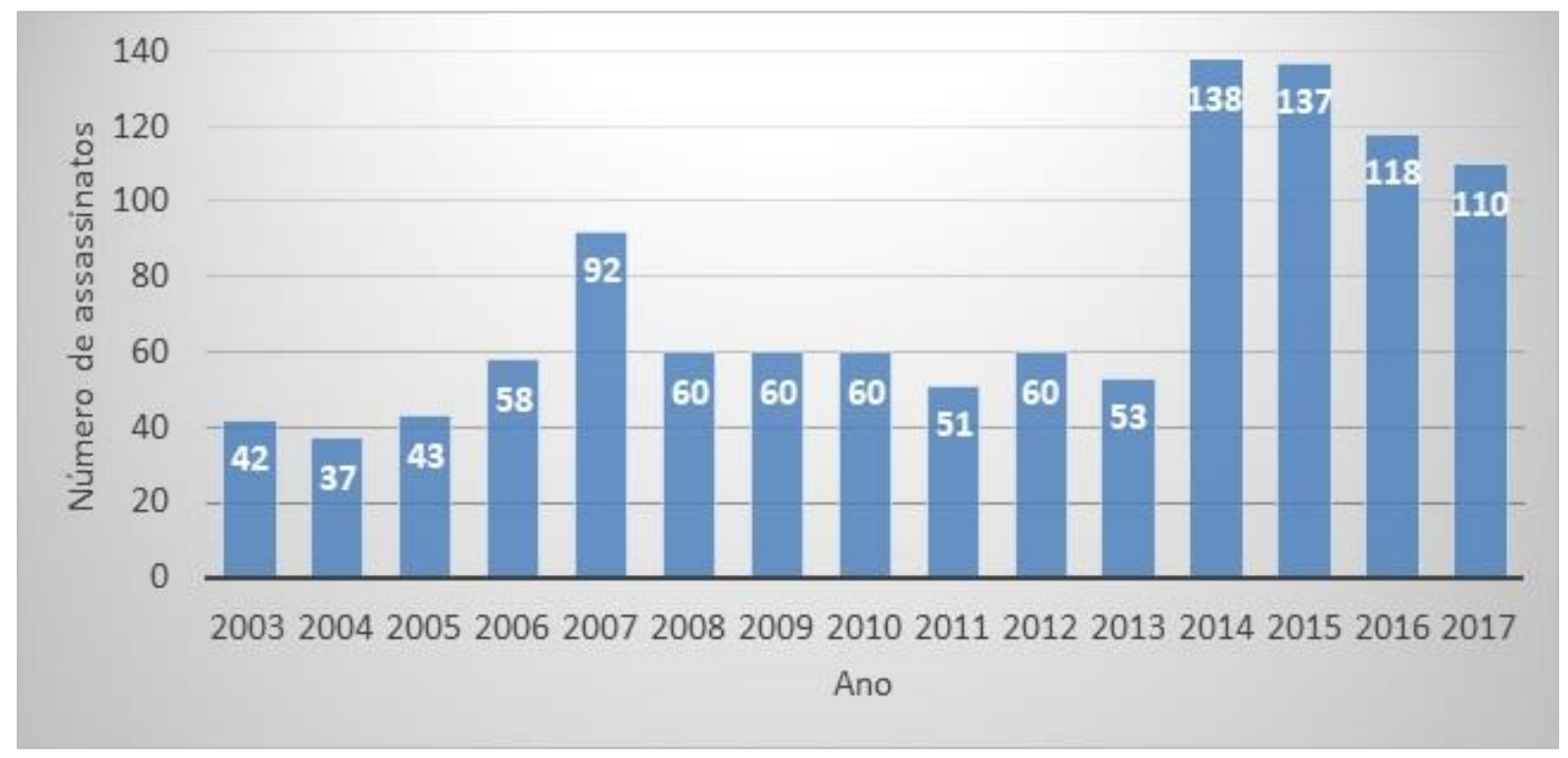

Fonte: CIMI, 2017. Organização: própria.

Em Alagoas, também foram registrados assassinatos, embora em patamar bem inferior aos números encontrados em outros estados do país. Parte das ações que resultaram em deliberada subtração da vida dos indígenas de Alagoas guarda íntima relação com a luta pela retomada de suas terras e construção do território. A partir dos dados disponíveis no Relatório Violência contra os Povos Indígenas no Brasil (2017), divulgado pelo CIMI, é possível observar que entre 2006 e 2017 foram assassinados 12 indígenas em Alagoas, conforme se pode observar na figura 4.

\footnotetext{
${ }^{3}$ O MATOPIBA compreende os estados do Maranhão, Piauí, Tocantins e Bahia, abrangendo 337 municípios e se transformou numa das principais áreas de expansão do agronegócio no Brasil (Pereira; Pauli, 2016). Em razão disso, é onde radica, atualmente, um dos mais emblemáticos pontos de conflitos na atualidade, já que é ocupado há séculos por várias etnias indígenas.

$\begin{array}{lll}\text { Lima et al., } 2019 & \text { ISSN 0104-5490 } & 147\end{array}$
}


Figura 4: Quantidade de indígenas assassinados em Alagoas (2006-2017)

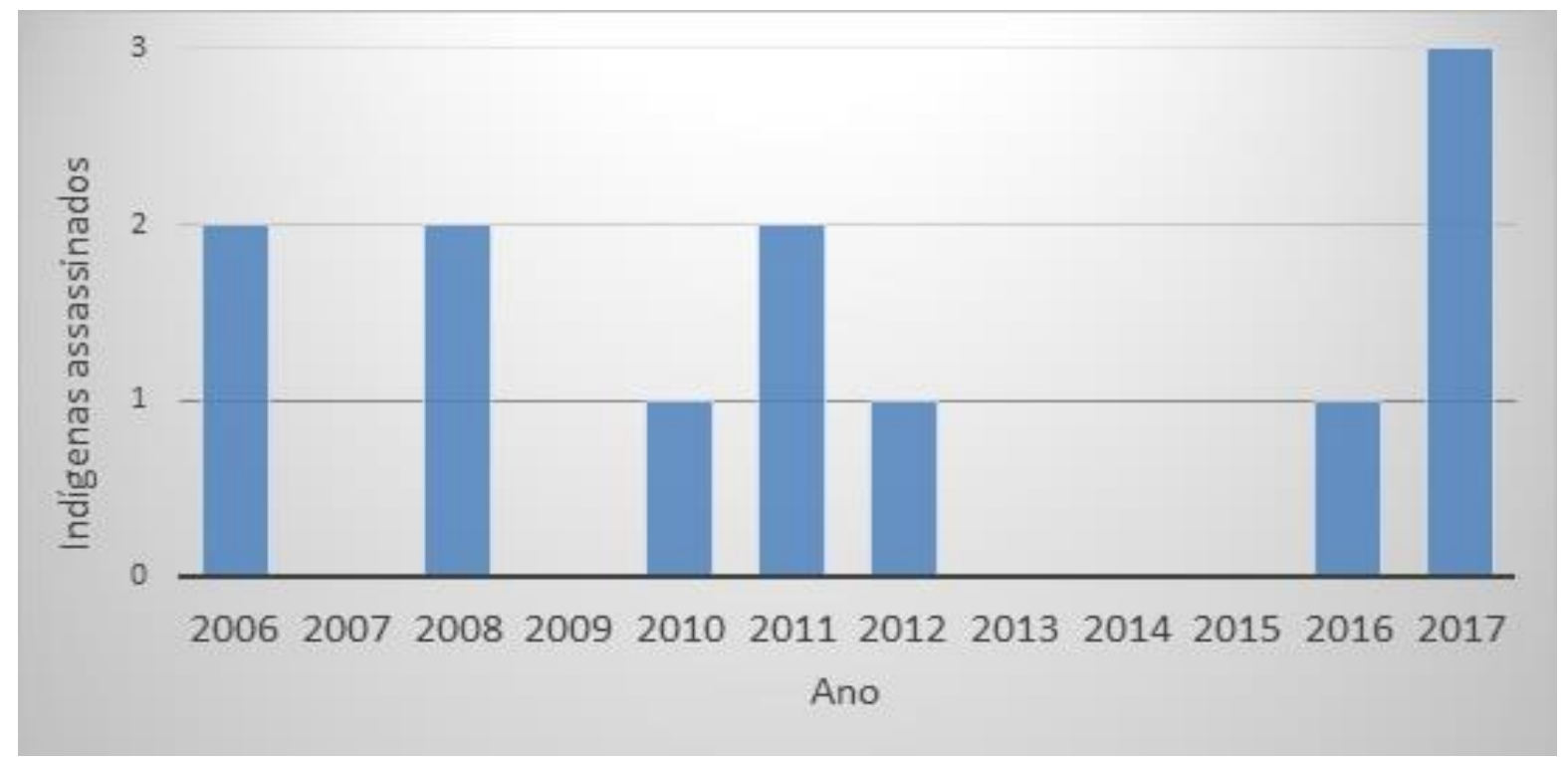

Fonte: CIMI, 2017. Organização: própria.

Xukuru-Kariri é a etnia com maior quantidade de indígenas mortos. De 2006 a 2017 foram subtraídas as vidas de seis membros, metade dos assassinatos do estado, conforme se pode observar na figura 5. Destaca-se o assassinato de João Natalício, liderança histórica do povo Xukuru-Kariri e do movimento indígena do Nordeste, brutalmente morto por golpes de faca, quando se preparava para ir ao roçado (O GLOBO, 2016).

Também merecem registro as mortes de um indígena da etnia Katokinn, atingido por vários tiros de arma de fogo, por dois homens, no ano de 2011, quando transitava por uma estrada vicinal, e de um indígena Kariri-Xocó, emboscado e morto por arma de fogo a 200 metros da aldeia onde morava. 
Figura 5: Membros de etnias vítimas de assassinato (2006-2017)

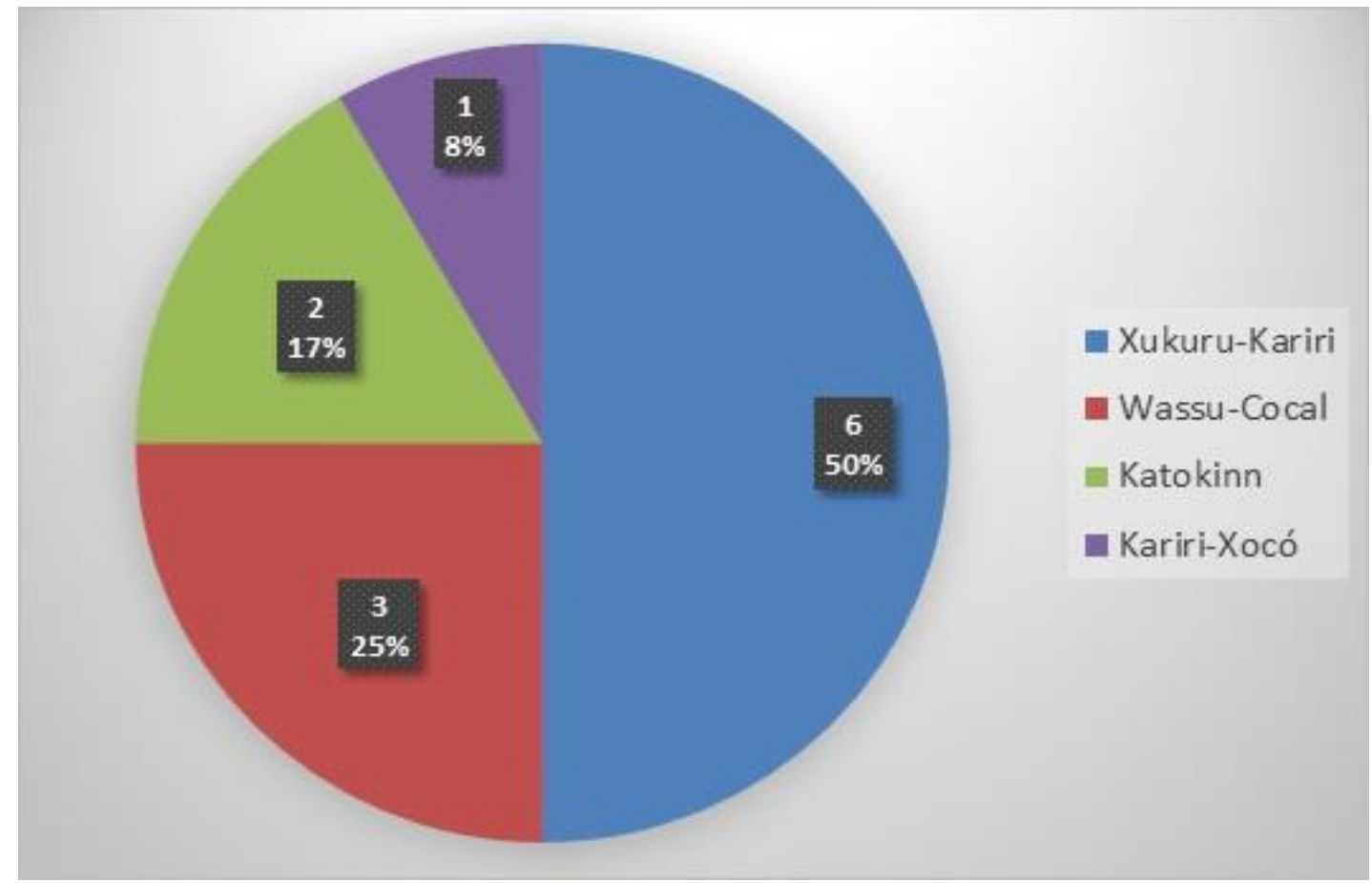

Fonte: CIMI, 2017. Organização: própria.

\section{CONSIDERAÇÕES FINAIS}

O extermínio de indígenas e a usurpação de suas terras é um fato inexpugnável da formação territorial brasileira e alagoana. Longe de figurar como um triste episódio do passado, os ataques às comunidades indígenas seguem seu compasso, engendrados pela tônica do capital, em aliança com o Estado.

$\mathrm{Na}$ contemporaneidade, intensifica-se a disputa territorial entre dois projetos antagônicos. De um lado, os indígenas estabelecem uma relação social que contraria o tempo célere, obstaculizando ou interditando a ofensiva sobre os elementos da natureza, a exemplo da água, do solo, dos minérios, da fauna e da flora. De outro, o capital, personificado em corporações empresariais de diversos ramos (mineral, construção civil, imobiliário, etc.) e fazendeiros criadores de gado, que contam com a anuência do Estado para a execução premeditada de crimes ambientais e crimes contra a vida, atingindo, frontalmente, os indígenas.

Em Alagoas, um estado conhecido pela presença das oligarquias de base agrária, que continuam a comandar a economia e o poder político, as etnias indígenas resistem, reivindicando, obstinadamente, as terras para a construção de seus territórios. O ônus da 
resistência é enorme, indígenas mortos e ameaçados de morte. Entretanto, os povos indígenas prosseguem como expressões vivas das contradições territoriais (Mizusaki, 2017).

\section{REFERENCIAS}

ALAGOAS. Secretaria de Planejamento e Gestão. Estudo sobre as comunidades indígenas de Alagoas. Maceió: SEPLAG, 2017.

ALAGOAS 24 HORAS. PF deflagra operação Wassu Cocal em Joaquim Gomes. 2012. Disponível em: <http://www.alagoas24horas.com.br/539998/pf-deflagra-operacao-wassucocal-em-joaquim-gomes/> Acesso em: 21 mai. 2018.

ALBUQUERQUE, C. F.; CANIELLO, M. d. M. Migração: a amarga vida de canavieiro do camponês do Semiárido. In: ALBUQUERQUE, C. F. d.; LUSA, M. G.; SILVA, M. E. F. d. (Orgs). Olhares: uma abordagem multidisciplinar sobre o semiárido alagoano. Maceió: Edufal, 2015, p. 43-72.

ALMEIDA, A. W. B. d. Universalização e localismo. Movimentos sociais e crise dos padrões tradicionais de relação política na Amazônia. Revista ABRA, ano 19, n. 1, p. 6-17, 1989.

ALMEIDA, M. R. C. d. Os índios na História do Brasil. Rio de Janeiro: Editora FGV, 2010. BARTOLOMÉ, M. A. As etnogêneses: velhos atores e novos papeis no cenário cultural e político. Revista Mana, Rio de Janeiro, v. 12, n.1, p. 39-68, 2006.

BRASIL. Constituição (1988). Constituição da República Federativa do Brasil. Brasília, DF: Senado Federal: Centro Gráfico, 1988.

Censo Demográfico 2010. Instituto Brasileiro de Geografia e Estatística - IBGE, 2010. Disponível em: <https://www.ibge.gov.br/estatisticasnovoportal/sociais/populacao/9662-censo-demografico-2010.html>. Acesso em: 02 de nov. 2017.

BETHONICO, M. B. M. Território e terras indígenas: uma breve reflexão a partir da Geografia. Revista de Geografia, Recife, v. 35, n. 2, 289-307, 2018.

CAMPOS, F. V. O processo histórico de luta pela terra dos índios Xukuru Kariri. In: ALMEIDA, L. S. d.; LIMA, C. d. S.; OLIVEIRA, J. d. S. (Orgs). Terra em Alagoas: temas e problemas. Maceió: Edufal, 2013, p. 67-88.

CIMI. Conselho Indigenista Missionário. Relatório Violência contra os Povos Indígenas no Brasil. 2011. Disponível em: <https://www.cimi.org.br/pub/relatorio/Relatorio-violenciacontra-povos-indigenas_2011-Cimi.pdf> Acesso em: 26 mai. 2018. 
Relatório Violência contra os Povos Indígenas no Brasil. 2014. Disponível em: $<$ https://www.cimi.org.br/pub/relatorio/Relatorio-violencia-contra-povos-indigenas_2014Cimi.pdf> Acesso em: 26 mai. 2018.

Relatório Violência contra os Povos Indígenas no Brasil. 2016. Disponível em: $<$ https://www.cimi.org.br/pub/relatorio/Relatorio-violencia-contra-povos-indigenas_2016Cimi.pdf> Acesso em: 27 mai. 2018.

Relatório Violência contra os Povos Indígenas no Brasil. 2017. Disponível em: <https://cimi.org.br/wp-content/uploads/2018/09/Relatorio-violencia-contra-povosindigenas_2017-Cimi.pdf> Acesso em: 6 nov. 2018.

CRUZ, V. d. C. Lutas sociais, reconfigurações identitárias e estratégias de reapropriação social do territó-rio na Amazônia. Niterói, RJ: Programa de Pós-Graduação em Geografia da Universidade Federal Fluminense, 2011. Originalmente apresentada como tese de doutorado, Universidade Federal Fluminense, 2011.

ECODEBATE. MPF/AL obtém condenação de pecuarista sergipano por crime ambiental em área indígena. 2010. Disponível em: <https://www.ecodebate.com.br/2010/08/19/mpfalobtem-condenacao-de-pecuarista-sergipano-por-crime-ambiental-em-area-indigena/> Acesso em: 26 mai. 2018.

FUNAI. Coordenação Regional Nordeste I. Informação sobre etnias indígenas de Alagoas. 2018. Disponível em: 〈https://esic.cgu.gov.br/sistema/site/index.aspx> Acesso em: 10 abr. 2018.

GALLOIS, D. T. Terras ocupadas? Territórios? Territorialidades?. In: RICARDO, F. (Org.). Terras Indígenas \& Unidades de Conservação da Natureza. 1 ed. São Paulo: Instituto Socioambiental, 2004, p. 37-41.

G1. Índios ocupam fazenda e denunciam ameaças em AL. 2011. Disponível em: <http://g1.globo.com/brasil/noticia/2011/04/indios-ocupam-fazenda-e-denunciam-ameacasem-al.html> Acesso em: 27 mai. 2018.

Índios denunciam contaminação de nascente na zona rural de Alagoas. 2015. Disponível em: <http://g1.globo.com/al/alagoas/noticia/2015/11/indios-denunciamcontaminacao-de-nascente-na-zona-rural-de-alagoas.html> Acesso em: 26 mai. 2018.

LIMA, L. G; SILVA, G. M. da; FEITOZA, G. do N. Mobilidade espacial do trabalho: redundantes do Sertão de Alagoas como parte da reprodução do capital. Revista Caderno de Geografia, Belo Horizonte, v. 28, n. 55, p. 1103-1121, 2018. 
LIRA, E. R. A geografia, o território capitalista e o território indígena. In: Simpósio Internacional de Geografia Agrária. Jornada Ariovaldo Umbelino de Oliveira, 2, 2015. Anais eletrônicos... Presidente Prudente: UNESP, 2015. Disponível em: <http://www2.fct.unesp.br/nera/publicacoes/singa2005/Trabalhos/Artigos/Elizeu\%20Ribeiro \%20Lira.pdf> Acesso em: 14 fev. 2018.

LUCIANO, G. d. S. O Índio Brasileiro: o que você precisa saber sobre os povos indígenas no Brasil de hoje. Brasília: Ministério da Educação; LACED/Museu Nacional, 2006.

MARTINS, J. d. S. O cativeiro da terra. São Paulo: Contexto, 2010.

MÉSZÁROS, I. Para além do capital: rumo a uma teoria da transição. 1 ed. São Paulo: Boitempo, 2002.

MIZUSAKI, M. Y. Movimentos indígenas, geografia e marxismo na questão agrária brasileira: quando "novos" personagens entram em cena. Revista NERA, Presidente Prudente, ano 20, n. 39, p. 39-59, 2017.

MONTENEGRO, J. Conflitos pela terra e pelo território: ampliando o debate sobre a questão agrária na América Latina. In: SAQUET, M. A.; SANTOS, R. A. (Orgs). Geografia Agrária, território e desenvolvimento. 1 ed. São Paulo: Expressão Popular, 2010, p. 13-34.

MORAES, A. C. R. Bases da formação territorial do Brasil: o território colonial brasileiro no longo século XVI. São Paulo: Hucitec, 2000.

O GLOBO. Em Alagoas, líder indígena é assassinado em área de conflito por terra. 2016. Disponível em: <https://oglobo.globo.com/brasil/em-alagoas-lider-indigena-assassinado-emarea-de-conflito-por-terra-2-20274848> Acesso em: 26 mai. 2018.

OLIVEIRA, A. U. d. A fronteira amazônica mato-grossense: grilagem, corrupção e violência. São Paulo: Iãnde Editorial, 2016.

OLIVEIRA, J. P. d.; FREIRA, C. A. d. R. A presença indígena na formação do Brasil. Brasília: Ministério da Educação, Secretaria de Educação Continuada, Alfabetização e Diversidade; LACED/Museu Nacional, 2006.

PEREIRA, L. I.; PAULI, L. O processo de estrangeirização da terra e expansão do agronegócio na região do MATOPIBA. Revista Campo-Território: revista de geografia agrária, ed. especial, p. 196-224, 2016.

PORTO-GONÇALVES, C. W. Latifúndio genético e a r-existência indígeno-campesina. Revista GEOgraphia, Niterói, v.4, n. 8, p. 1-15, 2002.

RIBEIRO, D. Os índios e a civilização: a integração das populações indígenas no Brasil moderno. São Paulo: Global, 2017. 
SANTANA JUNIOR, J. R. d. Produção e reprodução indígena: o vir e o porvir na reserva de Dourados/MS. Revista Campo-Território: revista de geografia agrária, v. 5, n. 9, p. 203 236, 2010.

SILVA, A. H. L. d. Terra, tradição e etnia: as estratégias de resistência dos Geripankó. In: ALMEIDA, L. S. d.; SILVA, A. H. L. d. Índios de Alagoas: cotidiano, terra e poder. Maceió: Edufal, 2009, p. 33-58.

SILVA JÚNIOR. A. B. d. Terra e cultura indígena: a construção de aldeamentos por uma identidade definida pela tensão. In: ALMEIDA, L. S. d.; LIMA, C. d. S.; OLIVEIRA, J. d. S. (Orgs). Terra em Alagoas: temas e problemas. Maceió: Edufal, 2013, p. 123-142.

SILVA, M. E. F. d. Terra parcelada, terra esfacelada: a desterritorialização do povo XucuruKariri em Palmeira dos Índios/AL. In: ALMEIDA, L. S. d.; SILVA, A. H. L. da. (Orgs). Índios do Nordeste: etnia, política e história. Maceió: Edufal, 2008, p. 115-136.

VIEIRA, J. L. G. et al. Povos indígenas em Alagoas: território, desterritorialização e reterritorialização. Mobilização política e afirmação étnica. In: ALMEIDA, L. S. d.; LIMA, C. d. S.; OLIVEIRA, J. d. S. (Orgs). Terra em Alagoas: temas e problemas. Maceió: Edufal, 2013, p. 181-206. 